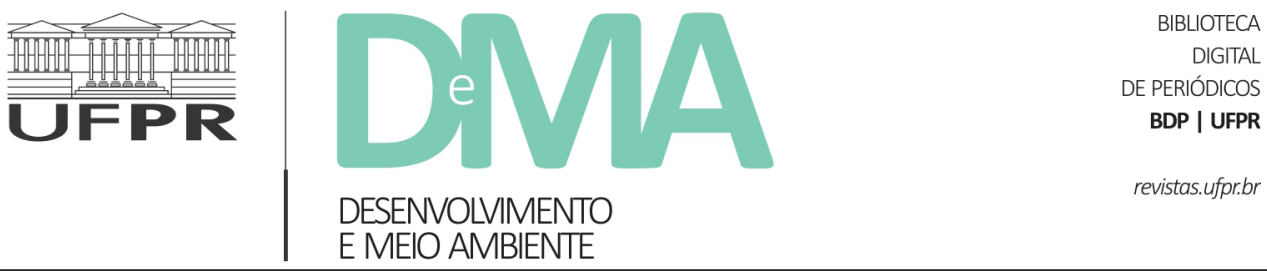

\title{
O modelo de tecnificação da política estadual de defesa civil em Santa Catarina: a trajetória do projeto JICA e os desastres ambientais no Vale do Itajaí
}

\section{The technification model of the state civil defense policy in Santa Catarina: the path of the JICA project and environmental disasters in the Itajaí valley}

\author{
Alexandre Evangelista SANTOS ${ }^{1 *}$, Isa de Oliveira ROCHA ${ }^{2}$ \\ ${ }^{1}$ Prefeitura Municipal de Porto Belo, Porto Belo, SC, Brasil. \\ ${ }^{2}$ Universidade do Estado de Santa Catarina (UDESC), Florianópolis, SC, Brasil. \\ *E-mail de contato: alexandree.santos@yahoo.com.br
}

Artigo recebido em 12 de fevereiro de 2021, versão final aceita em 27 de julho de 2021, publicado em 23 de dezembro de 2021.

RESUMO: $\quad$ O presente artigo pretende analisar o modelo de tecnificação adotado pela Defesa Civil de Santa Catarina. Trata-se de uma proposta que decorre da percepção de mudanças na Política Nacional de Proteção e Defesa Civil em 2012, em que o discurso tecnocientífico é inserido como matriz central da política nacional. O problema que se coloca é qual o objetivo dessa proposta, as mudanças que traz consigo e suas consequências. Para essa reflexão, o percurso que se seguiu foi a realização de um estudo de caso com escopo no pensamento da sociologia dos desastres. O caso selecionado foi o Projeto JICA, que tem papel relevante na organização da defesa civil de Santa Catarina. O estudo do JICA revela pistas importantes sobre o sentido que a PNPDC pode estar adquirindo, por se tratar de uma experiência de referência nacional. Para o estudo, foi realizada a revisão teórico-bibliográfica do contexto de emergência do Projeto JICA, o processo de sua implantação e o papel que esse processo teve no desenvolvimento da política estadual de defesa civil. Ainda, foram feitas entrevistas em que se buscou analisar a conformação do debate político em debate técnico, além da confrontação de dados documentais, como o Plano Plurianual, o Estudo Preparatório para o Projeto de Prevenção e Mitigação de Desastres na Bacia do Rio Itajaí e reportagens de grande circulação publicadas em 2015, para levantar os impactos produzidos por essa mudança. O estudo aponta que o marcador "proteção", como conceito orientador da política de defesa civil, encobre um conjunto de interesses em disputa no poder político, nos quais os setores empresariais têm vantagem ao assumirem o discurso tecnocientífico como ferramenta precisa de confrontação. Como decorrência, os seus interesses se generalizam como interesse geral da população 
atingida, concentrando poder político. Foram levantadas várias consequências desse processo, das quais, a mais cruel, é o uso do sofrimento das vítimas dos desastres.

\section{Palavras-chave: Defesa Civil; projeto JICA; Santa Catarina.}

ABSTRACT: This article deals with the analysis of the technology model adopted by the Civil Defense of Santa Catarina. It is a proposal that stems from the National Policy for Civil Defense and Protection in 2012 changes perception, where the technoscientific discourse is inserted as a central matrix of national policy. The problem that arises is the purpose of this proposal, the changes it brings, and its consequences. To propose this reflection, the path that followed was the realization of a case study with scope in the thinking the sociology of disasters. The selected case was the JICA Project, which has a relevant role in the civil defense organization of Santa Catarina. The JICA study reveals significant clues about the meaning that a PNPDC may be acquiring, as it is an experience of national reference. For the study, a theoretical and bibliographic review of the emergency context of the JICA Project was carried out, the process of its implementation, and the role that this process had in the development of the state civil defense policy. It was also identified that it sought to analyze the conformation of the political debate in a technical debate, in addition to documentary data confrontation, such as the Pluriannual Plan, the Preparatory Study for the Project for Disaster Prevention and Mitigation in the Itajaí River Basin, and reports of great dissemination in 2015, to raise the important impacts of this change. The study points out that the marker "protection" as a guiding concept of civil defense policy covers a set of interests in dispute in political power, where business sectors have an advantage in assuming the technoscientific discourse as a precise tool for confrontation. As a result, his interests are generalized as the general interest of the affected population, concentrating political power. This process raised several consequences, the cruelest being the usage of disasters victims suffering.

Keywords: Civil Defense; JICA Project; Santa Catarina.

\section{Introdução}

No tempo, as concepções sobre o tema defesa civil sofreram mudanças profundas. Para ilustrar essa percepção, pode-se usar como evidência o lançamento da última versão da Política Nacional de Proteção e Defesa Civil (PNPDEC), de abril de 2012, cuja principal contribuição é a adoção de conceitos ligados ao Gerenciamento de Riscos e Desastres, dando ênfase à noção de "proteção".

Na PNPDEC, proteção é definida como o conjunto de ações preventivas, de socorro, assistenciais, reabilitadoras e reconstrutivas destinadas a evitar desastres ou minimizar seus impactos para a população e restabelecer a normalidade. Esse destaque é importante ao tema porque reafirma o novo paradigma assumido pelas pesquisas: a perspectiva do desastre como produto social.

A concepção socioambiental reorganiza o campo de ação, ora dominado por atitudes reativas, centradas nas fases de resposta e reconstrução, para desenvolver estratégias de prevenção, mitigação e preparação. A responsabilidade do enfrentamento das crises é transferida para a população, de modo que solucionar o sinistro depende da própria capacidade da população lidar com o produto da sua atividade, aprendendo sobre as determinações envolvidas na produção dos riscos. Isso fica evidente com a fórmula: Risco = Ameaça $x$ Vulnerabilidade, em que se rompe a ideia do risco enquanto unicamente ameaça natural e se coloca a condição relacional de múltiplos processos e fatores sociais em 
suas determinações, como acesso a bens e serviços, renda, ocupação espacial etc.

O primeiro estágio de inserção de fatores sociais na concepção dos desastres teve referência em 1988 com a instalação do Sistema Nacional de Defesa Civil (SINDEC). A abordagem sistêmica adotada identifica a necessidade de permanente articulação das ações de prevenção, mitigação, preparação e reconstrução, configurando uma gestão integrada diante dos desastres. Esse processo seguiu novas atualizações em agosto de 1993 e com o Decreto $\mathrm{n}^{\mathrm{o}} 5.376$, de 17 de fevereiro de 2005. No desenvolvimento do SINDEC, o Governo apresentou, nos marcos legais, um reflexo de avanços internacionais ao incluir fatores sociais na produção dos riscos e desastres.

A compreensão da questão, a partir dessa perspectiva, desdobrou-se na busca por ampla participação, mobilizando os mais variados setores da sociedade, para encontrar soluções coletivas para o problema. Essa operação materializou-se na confecção da Conferência Geral sobre Desastres para Prefeitos, Dirigentes de Instituições Públicas e Privadas e Líderes Comunitários, em 2002, nos Núcleos Comunitários de Defesa Civil (NUDEC), em 2005, e na $1^{\circ}$ Conferência Nacional de Defesa Civil, em 2010.

Apesar de a política seguir uma concepção que visa ampla participação social, chama a atenção uma mudança significativa, a partir de 2012, quando surgem novas configurações dessa participação na política de defesa civil. Nela, ocorre maior especialização no debate, sendo realizada uma leitura mais técnica das ações, principalmente no campo do monitoramento dos fatores climáticos, o que muda o sentido da política de defesa civil. Portanto torna-se relevante analisar o modelo de tecnificação da defesa civil para tornar visível o sentido que ela vem adquirindo e saber quais as suas consequências.

A proposta deste artigo se insere no campo teórico da sociologia dos desastres e foi realizada por meio de estudo de caso do Projeto JICA que tem relevância nacional por ser referência na produção dos sistemas de defesa civil em produção no país. O Projeto JICA é o nome como ficou conhecido o relatório The Itajai River Basin Flood Control Project, apresentado pela Agência de Cooperação Internacional do Japão (JICA) à Santa Catarina em 1986. Compreende-se que a análise detalhada da produção desse projeto dá sentido ao processo de tecnificação da defesa civil que se pretende reconstruir neste trabalho.

Para essa realização, foi feita a revisão teórico-bibliográfica do contexto de emergência do Projeto JICA, o processo de implantação e o seu papel no desenvolvimento da política estadual de Defesa Civil de Santa Catarina; a análise sobre a conformação desse debate político em debate técnico, por meio de pesquisa de campo e entrevistas não estruturadas, realizadas em 2013 na Secretaria de Estado de Defesa Civil; e a análise dos principais impactos do modelo de tecnificação da política de defesa civil estadual, confrontando as informações obtidas, por meio de dados documentados pelo Plano Plurianual - 2012-2015 - da Secretaria de Estado da Defesa Civil, do Estudo Preparatório para o Projeto de Prevenção e Mitigação de Desastres na Bacia do Rio Itajaí, assessorado pela JICA, e de reportagens de grande circulação publicadas em 2015.

Como resultado, este estudo aponta que a preocupação da PNPDC, em marcar a noção de proteção como principal conceito orientador em sua política, encobre um conjunto de questões ligadas aos interesses dos atores envolvidos. No jogo do 
poder, os setores empresariais perceberam essa dinâmica e encontraram seu espírito protagonista, assumindo o discurso tecnocientífico como uma ferramenta precisa de embate e conformação da organização dos seus interesses no poder público. $\mathrm{O}$ resultado traz um conjunto de consequências graves, sendo, a mais cruel, o sofrimento da população mais vulnerável, que fica marginalizada e distante de qualquer possibilidade de romperem a sua condição de vítimas de desastres.

\section{O ciclo das barragens}

Para remontar o contexto de emergência e o desenvolvimento do Projeto JICA em Santa Catarina, é preciso analisar o protagonismo dos setores industriais e comerciais na origem da tecnificação da Defesa Civil. A importância se deve à forma ativa que tiveram na definição de várias diretrizes políticas no governo ao longo do tempo. Esse protagonismo tem como primeiro impacto a cisão entre a dimensão natural e a dimensão social no Vale do Itajaí, buscando saídas governamentais para os prejuízos provocados pelos desastres e, ao mesmo tempo, conformando medidas desiguais na confrontação e redução dos riscos de desastres.

Como norma, o padrão de política pública em Santa Catarina seguia restrito à fase de resposta, e a ênfase dada, como política governamental, fundamentava-se dentro do conceito do desastre como natural, considerado como inevitável. Nesse sentido, os mecanismos públicos eram deflagrados apenas quando o acontecimento ocorria, resultando em uma ação fragmentada e descontínua, pois ficava sujeito aos recursos públicos disponíveis.

Mattedi (1999) esclarece que a consequência mais evidente desse processo está no encobrimento das responsabilidades sociais na intensificação dos desastres, mecanismo que se expressa na externalização dos danos. O autor define o conceito de externalização dos danos como "[...] o processo através do qual a comunidade impactada redistribui os custos associados às atividades de recuperação e preparação provocados pela ocorrência do problema" (Mattedi, 1999, p. 137). Dessa maneira, a atuação governamental se manifesta na forma como se organiza a compreensão do fenômeno e de suas consequências, o capital político é convertido nas ações e estratégias de enfrentamento.

A forma como ocorre a externalização dos danos é, em Santa Catarina, canalizada pelo protagonismo dos setores empresariais na disputa ${ }^{1}$ pelo poder político do estado. Considerando que a capacidade de reivindicação depende fortemente da influência dos atores sociais nas relações de poder, a organização das medidas adotadas como resposta e reconstrução acabam desiguais, porque parte da sociedade não tem os seus interesses representados no campo decisório do poder político. Consequentemente, as formas de organização estatal dos planos de contingências seguirão a lógica da classe dominante de cada época.

Quando uma situação de emergência é representada como um problema produzido pela natureza, a responsabilidade da sociedade em seu agravamento não é levada em conta. Assim, o tratamento encobre o fato de que nem todos os setores sociais são atingidos e

\footnotetext{
${ }^{1}$ Definimos setores empresariais principalmente pela composição das elites industriais e comerciais do Vale do Itajaí. Essa região se conforma em Santa Catarina como um dos principais polos econômicos, chegando a ser o segundo polo têxtil do país.
} 
beneficiados da mesma forma, como exemplifica a execução de uma obra de melhoramento fluvial. O aumento da vazão em um trecho específico do rio pode diminuir o impacto das situações de emergência em determinada região e transferir os seus efeitos destrutivos para outras regiões. Sua execução encobre a operação de mecanismos de distribuição das perdas e concentração dos beneficiados. (Mattedi, 1999, p. 138)

Frank (1995), por exemplo, apresenta uma série de registros de enchentes na cidade de Blumenau desde 1852, afirmando que "A história das enchentes [...] caminha lado a lado com a história da colonização e do seu desenvolvimento" (Frank 1995, p. 33). Apesar da constatação, as situações de emergências não foram suficientes para desencadear a estruturação de sistemas defensivos adequados ao acontecimento, mostrando que só esse fator não é o determinante fundamental para mobilizar o investimento público. Diante do sinistro, a inércia governamental é conveniente para os setores dominantes, pois provoca sentimentos de insatisfação e manifestações de impasses sociais. Esse caldo fervilhante dá legitimidade aos setores organizados, como o setor empresarial, de modo que a população afetada se mobiliza em torno deles e de seus interesses, passando a tratar esses interesses como interesses gerais da região.

No caso da sociedade capitalista, esse processo segue a lógica da defesa do seu modo de produção, garantido o funcionamento do mercado. Valencio (2016, p. 42) afirma que:
Quando deflagram um desastre, o meio jurídico desses sistemas age para garantir, em primeiro lugar, os interesses corporativos; tudo se passa como se um "mal maior" tivesse que ser evitado, qual seja, a eventual inviabilidade econômica da empresa para a continuidade de suas operações (Valencio, 2016, p. 42).

Essa tendência de defesa de interesses corporativos pode ser observada na década de 1920, em que dois projetos deram vazão à produção desse cenário de concentração de poder e ruptura do modelo de resposta aos desastres em Santa Catarina. Trata-se dos projetos de Otto Rohkohl e Adolf Odebrecht, que surgiram com diferentes soluções ao problema das enchentes do Vale do Itajaí, sem convergirem em unidade de ação. As diferenças não se deram tanto por serem soluções distintas, mas pelos interesses em disputa. Rohkohl era representante dos setores industriais e comerciais, por isso, percebeu rapidamente que as enchentes comprometiam o crescimento econômico da região e, diante desse problema, apontou para uma solução. Ele considerou que a situação poderia ser resolvida mediante a construção de barragens para conter as cheias do Rio Itajaí-Açu, a montante da cidade de Blumenau². O governo estadual considerou a proposta, mas não previu o dano intermitente aos territórios do Alto Vale do Itajaí, que seriam inundados por essa medida. Nesse momento, as frentes de colonização europeia do Alto Vale reivindicaram o seu direito e forçaram a mediação do governo federal no assunto.

Surgiu então um conflito sobre as medidas que seriam adotadas, cujo impasse não foi tratado por uma ampla discussão sobre o tema. E ao contrário

\footnotetext{
${ }^{2}$ Formado pelo encontro dos rios Itajaí do Oeste e Itajaí do Sul, em Rio do Sul, o Rio Itajaí-Açu é o maior curso de água da Bacia Hidrográfica do Itajaí. Da nascente principal até a foz, ele percorre cerca de $200 \mathrm{~km}$ e é de grande importância econômica por comportar o principal porto do estado e o segundo maior porto em movimentação de contêineres do país (FUNDAÇÃO AGÊNCIA DE ÁGUA DO VALE DO ITAJAÍ, 2010).
} 
da abertura de espaços de participação social, o governo federal nomeou um interventor ligado ao Ministério da Viação e Obras Públicas (19221926), o itajaiense Victor Konder, para defender os interesses das frentes de colonização. Konder não aceitou a proposta de construção de barragens e designou o engenheiro Adolf Odebrecht para projetar outras medidas. Os setores empresariais da região ainda não haviam conquistado sua força política e tiveram que aceitar a derrota. O contraponto de Odebrecht veio por meio de um plano de aceleração do escoamento das águas do Rio Itajaí-Açu. Para torná-lo consensual, argumentou que a medida seria mais eficaz do que a construção de barragens, além de transferir os custos aos cofres públicos (Frank, 1995). Porém nenhuma das soluções chegou a ser executada nesse período e todos os projetos foram abandonados com a Revolução de 1930.

Segundo Mattedi (1999), o ponto mais original da proposta de Rohkohl residia na concepção do modelo político-institucional de implantação das medidas de proteção, levando a ruptura do modelo centrado no desastre natural e indicando a necessidade de autonomia social. Isso deu vantagem aos setores empresariais que aprenderam com ele que o padrão de desenvolvimento da região não poderia depender das descontinuidades de inversão de recursos do poder público, sugerindo a mobilização da própria comunidade para implantar meios alternativos para gerenciar o problema. A sua proposta enfatizava o espírito protagonista do empresariado regional, levando o seu projeto a uma boa repercussão. ${ }^{3}$
Durante o Estado Novo, ocorriam dois processos contraditórios: a expansão industrial e a pouca capacidade dos setores empresariais e comerciais representarem seu interesse no poder político. O domínio se centrava nas famílias latifundiárias do planalto catarinense, marginalizando os empresários do Vale e do Norte de Santa Catarina. Apesar da ascensão e do dinamismo da industrialização, "as classes empresariais não haviam alcançado um estágio de consciência capaz de produzir políticas claramente com "orientação de classe". [...] Os industriais ainda eram um grupo pequeno dentro da sociedade brasileira" (Skidmore, 2010, p. 117). Era preciso disputar o espaço político, situação vista na formação econômica catarinense.

As condições políticas para a ascensão dos setores empresariais foram colocadas após 1945, com o dinamismo dos setores industriais e comerciais alavancados pela nova fase do capitalismo, que teve a industrialização como motor do seu desenvolvimento. Com isso, coloca-se a possibilidade de retomar a pauta empresarial sobre organizar medidas de confrontação dos desastres do Vale do Itajaí. Em 1957 (Fraga, 2002), o projeto de Rohkohl é retomado e abre-se o "ciclo das barragens".

Apesar da conquista, os setores empresariais ainda enfrentaram dificuldades na sua caminhada, com o processo de implantação dos projetos das barragens se arrastando por anos. As condições favoráveis voltaram apenas mediante as enchentes de 1961, ocasião de novas mortes e perdas materiais. João Goulart, presidente à época, sobrevoou a região inundada e, finalmente, as barragens,

\footnotetext{
${ }^{3}$ Imigrante alemão que veio morar no Brasil em 1907 para dirigir a implantação da Estrada de Ferro de Santa Catarina. Foi cônsul alemão entre 1913 e 1938, trabalhou em várias empresas de destaque em Blumenau, tendo sido diretor da Empresa Força e Luz Santa Catarina: foi um dos fundadores da Eletro Aço Altona e da fábrica de gazes Cremer S/A.
} 
com a melhoria da infraestrutura de controle de rios e afluentes, começaram a sair do papel. Ainda assim, das cinco barragens relacionadas no projeto inicial de Rohkol, somente três foram concluídas: a Barragem Oeste, localizada acima da cidade de Taió, com obras iniciadas em 1964 e concluídas em 1973; a Barragem Sul, localizada na cidade de Ituporanga, iniciada em 1966 e concluída em 1975; e a Barragem Norte, localizada em José Boiteux, iniciada em 1976 e concluída em 1992.

\section{O projeto JICA}

O Projeto JICA (Japan International Cooporation Agency) é um termo de cooperação entre Santa Catarina e Japão. A iniciativa tem base na atuação do governo catarinense diante das enchentes de julho de 1983 e agosto de 1984. Essas catástrofes são as marcas mais emblemáticas da capacidade destrutiva das enchentes até aquele momento: foram dias de sofrimento, quando $68 \%$ da população do estado

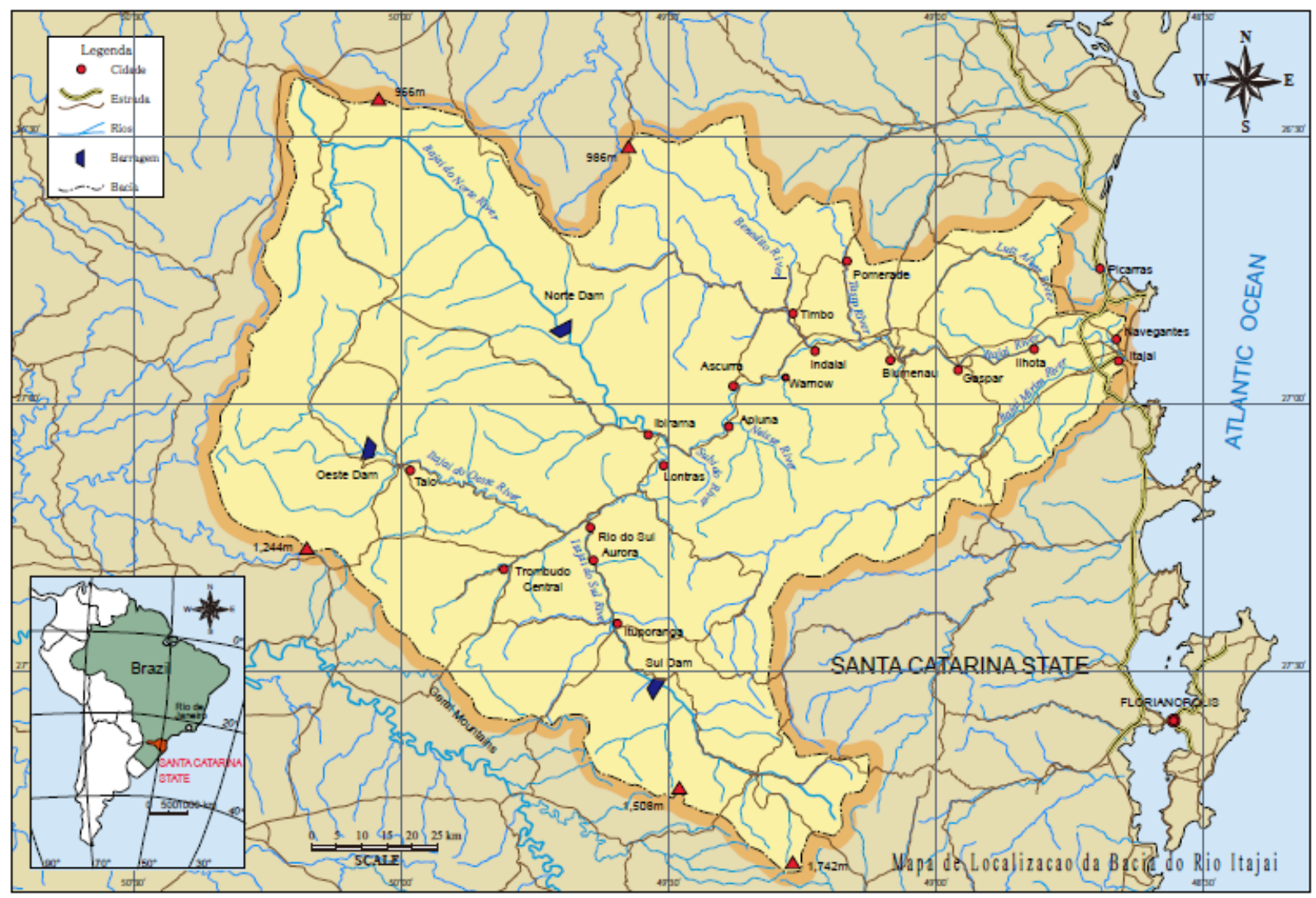

FIGURA 1 - Representação gráfica das barragens da bacia do Rio Itajaí-Açu.

FONTE: JICA (2011). 
foi atingida, com 65 mortes e 353 mil desabrigados e desalojados. A profunda repercussão e comoção nacional se enraizou na memória social, reabrindo processos de tensão e ações nas regiões afetadas.

Nesse período, o governo estadual, ainda não alinhado com os setores empresariais do Vale do Itajaí, respondeu aos acontecimentos com o Programa Especial de Reconstrução do Estado de Santa Catarina e com a criação de órgãos executivos, como o Conselho Extraordinário de Reconstrução e a Secretaria Extraordinária da Reconstrução. Porém, ao conduzir esse programa, não estava previsto o levante dos anseios gerais da população atingida.

Após as enchentes de 1983-1984, imediatamente a Secretaria Extraordinária da Reconstrução foi mobilizada e apresentou vários relatórios sobre os prejuízos ocorridos na região, o que deu base para a realização de vários seminários para discutir as avaliações feitas e formular novos projetos para a redução de riscos e desastres. Conforme assinala Frank (1995), durante os seminários, houve impasses apresentados pelos participantes, que criticaram a limitação do governo em manter apenas ações voltadas às fases de resposta e reconstrução. Apesar da construção de barragens e melhorias fluviais, iniciados por João Goulart no ciclo das barragens, o modelo de defesa civil em Santa Catarina seguia a política do Ministério do Interior, intervindo nas regiões afetadas por meio da prestação de socorro, atendimento assistencial, assistência alimentar e hospitalar, moradia provisória e vestuário. Nesse sentido, o governo foi surpreendido durante os seminários com a intensa participação e os apelos de vários setores atingidos para ampliar a política de defesa civil, principalmente em ações de prevenção.

A experiência de redemocratização dos anos 1980 possibilitou uma inovação no interesse so- cial, estabelecendo intensa participação de novos segmentos e setores nas políticas públicas. Com isso, os acontecimentos nesse período ensejam a emergência de novos atores para representação no debate: associação de moradores, associações profissionais, sindicatos, pesquisadores universitários e associações de defesa do meio ambiente.

Nenhuma mudança ocorreria se não houvesse um processo particular de confrontação aos desastres no Vale do Itajaí que provocasse transformações importantes para a estruturação da política de defesa civil catarinense. Diante dos apelos, o governo aceitou as reivindicações dos seminários e propôs o lançamento de um consórcio. À época, ele tinha como objetivo a Elaboração de um Plano Global Integrado para a Bacia de Itajaí, envolvendo os entes federativos. Também era prevista a participação social, definida aqui como as classes produtoras e trabalhadores, a sociedade civil e a comunidade civil.

A democratização do debate era importante, visto que a movimentação produzida pelas enchentes, para tanto, tinha a intenção de descentralizar a elaboração das metas a serem definidas como respostas às angústias sociais. A ideia foi formalizada em 1985 com o Plano Global e Integrado de Defesa contra Enchentes (PLADE), segundo Frank (1995), menos participativo do que havia sido previsto nos seminários. E apesar da iniciativa chegar a aprovar uma interessante proposta, a Resolução n 30/1985, prevendo a instalação de comitês de bacias, com foco voltado às questões socioambientais e ao modelo de desenvolvimento econômico regional, nada foi feito. Em resumo, as ações realizadas promoveram apenas o aproveitamento político dos acontecimentos, sem chegar a incorporar decisões efetivas de mudanças. 
A menor participação não parece acidental,

Embora a literatura assinale que o altruísmo seja o comportamento social preponderante em contexto de desastre, outros casos de catástrofes no Brasil demonstraram que, passado um breve período de uma reabilitação emergencial, as medidas recuperativas foram limitadas e o abandono das vítimas foi a regra, pois a marginalização histórica dos afetados autorizava a prática de slow violence contra os mesmos. Denominar as medidas usuais de reabilitação como "assistência humanitária" deixa escapar a dimensão da cidadania e o fato de que os programas humanitários pouco lutam pelo justo ressarcimento àqueles que tudo perdem numa tragédia. (Valencio, 2016, p. 42)

A regra do abandono, citado por Valencio, foi seguida. Em resumo, as ações realizadas promoveram mais uma vez o aproveitamento político dos acontecimentos, sem chegar a incorporar decisões que resultassem em mudanças.

$\mathrm{O}$ abandono do governo não diminuiu a mobilização social e os impasses continuaram com os setores mais organizados à frente. Nesse momento, as classes empresariais assumiram posição e mobilizaram-se para manter níveis de tensões ao poder público. A Associação Comercial Industrial (ACIB) fez a frente de liderança lançando a campanha permanente: "A solução não cai do céu". Ela resgatou, com isso, o espírito empreendedor de anos anteriores e, por meio de sua representatividade e legitimidade, acionou entidades, órgãos de comunicação, associação de classes, clubes de serviços e voluntários em torno do tema. Com a confecção de uma campanha nacional, em outubro de 1984, conseguiu que prefeitos e associações comerciais financiassem a vinda de jornalistas dos principais órgãos de comunicação do país, realizando várias reportagens que evidenciaram a falta de apoio go- vernamental. Em 1985, sem saber ao certo se motivado pela campanha, o vice-prefeito de Blumenau, engenheiro Paulo Oscar Baier, é nomeado diretor do Departamento Nacional de Obras de Saneamento (DNOS) (Frank, 1995, p. 66-67), com isso, a campanha consegue emplacar o lobby de investimentos públicos pretendido.

Consolida-se, assim, a iniciativa empresarial do Vale do Itajaí como grupo dominante na organização do governo, retomando o velho projeto das obras estruturais dos afluentes do Rio Itajaí-Açu. Portanto a ação mais imediata do governo federal foi direcionar parte dos investimentos para concluir o projeto de Rohkoh, nas obras da barragem de contenção no Norte, localizada em José Boiteux, iniciando em 1976, no "ciclo das barragens", e parte para firmar um convênio com a Agência Internacional de Cooperação do Japão (JICA), consolidando o debate no campo tecnocientífico. Inclusive, essa foi a justificativa dada para a necessidade do convênio. O Departamento Nacional de Obras e Saneamento (DNOS) alegou falta de capacidade técnica para ação governamental daquela monta para enfrentar as adversidades ocorridas em Santa Catarina.

Destaca-se, nessa passagem, uma segunda consequência da tecnificação da defesa civil, qual seja, a sua mercantilização. A cooperação entre o Brasil e o Japão marca essa transição, enquanto dá condições para estruturação de um mercado, por meio de projetos de contingenciamento que se tornam mercadorias para captação de financiamento público e privado. E não apenas isso, a JICA constitui uma ferramenta importante ao mercado Japonês, como um braço institucional do governo até 2008 , e do mercado privado depois, ao se tornar uma instituição independente. O objetivo era a prestação de auxílio ao desenvolvimento de 
países em desenvolvimento por meio de construção de infraestruturas, assistência técnica e linhas de financiamentos. O que se opera com a agência é a expansão do mercado japonês, oportunizando acesso privilegiado das suas empresas à economia de outros países (Chiarelli, 2009).

Os estudos da JICA apontaram necessidades, como o melhoramento fluvial, por meio de medidas estruturais, e o planejamento hidrográfico, como medidas não estruturais. Foram selecionados para implantação os trechos entre Blumenau, Gaspar, Ilhota, Itajaí, Ascurra, Rio do Sul, Lontras, Ituporanga e Brusque. Na época, para implantar as medidas estruturais, principalmente no tocante à melhoria fluvial, a JICA recomendou a contratação de empréstimos na casa de 190 milhões de dólares. Mesmo com toda a movimentação, os investimentos não foram contratados e as ações novamente foram abandonadas em 1987, quando o estado passou a ser governado por Pedro Ivo Campos. $\mathrm{O}$ argumento para a mudança de planos era a intenção de dar características próprias ao governo catarinense. A continuação de qualquer medida de redução, minimização e reconstrução das consequências dos desastres só voltaria à pauta com o ex-prefeito de Blumenau, engenheiro Vilson Pedro Kleinübing, eleito governador de Santa Catarina para o mandato 1990-1994, pela coligação União por Santa Catarina (PFL, PDS e PTB).

No seu governo, o PLADE foi retomado, sofrendo reformulações em 1991, com a integração da equipe técnica estadual e resgatando a cooperação com a Japan International Cooperation Agency (JICA). A equipe técnica formulou a sua proposta no documento The Itajai River Basin Flood Control Project, sendo, esta, o resultado do primeiro levantamento feito pela JICA em Santa Catarina. Essa cooperação fundamentou a adoção de um complexo de medidas formando um plano diretor de controle das enchentes no Vale do Itajaí, chamado de Master Plan (Fraga \& Köhler, 1999).

\section{A racionalização técnica da politica de defesa civil}

A reformulação do PLADE, no primeiro lustro da década de 1990, no governo Kleinübing, indicou duas direções: 1) o Programa de Controle de Cheias e Proteção de Vales e Cidades, baseado no Projeto da JICA; e 2) o Programa de Recuperação Ambiental, organizado pelo Programa Microbacia, desenvolvido pela Secretaria de Estado da Agricultura; no Programa de Recuperação Ambiental da FATMA 4 ; e no projeto chamado Ecoitajaí. Em vez dessas direções, o governo decidiu novamente por executar a indicação dos setores empresariais, mantendo investimentos em medidas estruturais de recuperação e controle das enchentes no Vale do Itajaí, deixando as medidas não estruturais para outro momento. O PLADE, na verdade, era uma simplificação do projeto JICA, no qual descartava algumas medidas estruturais e todo o complexo de medidas não estruturais recomendadas (Mattedi, 1999).

A revisão feita pelo governo estadual da época originou a previsão de 490,2 milhões de dólares, dos quais, metade precisaria ser arrecadado em

${ }^{4}$ FATMA - Fundação de Amparo à Tecnologia e ao Meio Ambiente, instituição estadual do meio ambiente à época. 
forma de empréstimos. $\mathrm{O}$ valor colocou em risco a capacidade orçamentária, por isso, o governo desistiu da proposta. Esse recuo foi reforçado pela pressão de associações ambientalistas e do corpo técnico-científico do próprio governo, que também não concordaram com as medidas pretendidas. Sem muitas alternativas, o governo reduziu novamente a proposta, priorizando apenas algumas medidas. $\mathrm{O}$ plano final foi concluído em 1994, sendo chamado apenas de Projeto JICA. Ou seja, houve um recorte do plano original, que contemplava ações socioambientais, para reduzi-las a medidas estruturais de controle e contenção do fluxo das águas, sendo reduzido ainda mais pela inviabilidade orçamentária. Portanto o governo assumiu publicamente o seu interesse em desenvolver o Programa de Controle de Cheias e Proteção de Vales e Cidades, mas teve que se conter em concentrar esforços na execução de medidas estruturais de melhoramento do fluxo do rio, limitando sua ação aos trechos entre as cidades de Blumenau e Gaspar, e a cidade de Itajaí.

O reflexo prático desse processo ocorreu em 2008, quando aconteceu a maior tragédia registrada na história do Vale do Itajaí e uma das maiores já registradas pela defesa civil. A retirada das ações socioambientais e concentração em recortes do Programa de Controle de Cheias e Proteção de Vales e Cidades mostrou a face mais destrutiva do modelo de gerenciamento de riscos aplicados. Esse desastre não teve as enchentes como seu principal agente, mas o deslizamento de morros e encostas. A movimentação de terras resultou em 85 municípios em situação de emergência e outros 14 em estado de calamidade pública, afetando 1,5 milhão de pessoas, com 135 mortes, principalmente por soterramento, 78 mil desabrigados e desalojados. Imediatamente houve reação de vários setores, a exemplo do meio acadêmico, que contavam com especialistas dedicados na produção de estudos na área, apontando aquela situação como uma tragédia anunciada.

Entre as principais causas levantadas, estavam:

1) a "sobrecarga da capacidade assimilativa e regenerativa do ambiente natural"; 2) a "incapacidade cognitiva de identificar as causas"; 3) a "incapacidade política de formular e implementar estratégias de previsão e preparação para conviver com o problema"; 4) "o processo de gestão autoritário de formulação e implantação de políticas públicas que exclui a participação da sociedade organizada" (Ávila \& Mattedi, 2017, p. 17).

O governo estadual se mobilizou diante das críticas, formando naquele ano o Grupo de Reação, cuja função principal era buscar convergência entre as três esferas de governo para planejar e executar ações de socorro e reconstrução (Casagrande Jr., 2008).

Dissipado o caráter emergencial, o grupo direcionou o trabalho na construção de projetos de médio e longo prazo, com a intenção de criar estratégias de prevenção. Para fazer uma avaliação das causas e efeitos dos acontecimentos ocorridos e traçar medidas de redução e minimização de desastres, o Grupo de Reação criou um Grupo Técnico-científico, vinculado à Fundação de Apoio à Pesquisa Científica e Tecnológica de Santa Catarina (Fapesc) e teve apoio estratégico da Empresa de Pesquisa Agropecuária e Extensão Rural de Santa Catarina (Epagri). A proposta do Grupo de Reação gerou impasses e o plano integrado de prevenção elaborado esbarrou nos Planos de Recursos Hídricos da Bacia do Itajaí, que estava sendo formulado desde 2004 pelo Comitê de Gerenciamento da Bacia 
Hidrográfica do Rio Itajaí, conhecido como Comitê do Itajaí (Guimarães, 2012).

O Comitê havia sido criado pelo Decreto Estadual 2.109, de 1997, em conformidade com a Política Nacional de Recursos Hídricos, Lei 9.433 de 1997, e pela Política Estadual de Recursos Hídricos equivalente, na Lei 9.748 de 1994, com objetivo de promover e articular ações de defesa contra secas e inundações, garantindo o fornecimento de água em quantidade e qualidade adequadas na Bacia Hidrográfica do Rio Itajaí-Açu. Para conciliar as propostas e vencer os impasses, o plano do Grupo de Reação foi entregue ao comitê para ser avaliado. A articulação das duas propostas e a finalização do projeto ficou a cargo da Fundação Agência de Água do Vale do Itajaí ${ }^{5}$, braço técnico do Comitê do Itajaí.

O grupo técnico da Fundação Agência de Água do Vale do Itajaí liberou uma linha de crédito para projetos associados aos sistemas de alerta e radares, para elaboração de planos de ocupação territorial e, também, para eventos e publicações. O principal produto desse trabalho foi o Plano Integrado de Prevenção e Mitigação de Riscos de Desastres Naturais na Bacia Hidrográfica do Rio Itajaí. Com base na Política Nacional de Defesa Civil, esse plano reuniu programas como: o desenvolvimento institucional com vistas à preparação para emergências e desastres; o monitoramento, alerta e alarme; a preparação, comunicação, motivação, mobilização para resiliência e diminuição da vulnerabilidade; a avaliação de redução de riscos de desastres; a redução dos riscos de desastres; e a recuperação de áreas afetadas por desastres. Novamente a JICA é chamada para auxiliar na operacionalização das ações (Guimarães, 2012).

O plano do governo em cooperação com a JICA foi entregue ao Comitê do Itajaí para revisão e este constatou que, na verdade, não se tratava de um estudo preparatório para a elaboração de medidas de redução e minimização de desastres, mas de um roteiro de ações que deveria ser seguido, evidenciando que o trabalho feito apenas atualizava a velha proposta do Projeto JICA. No documento, o Comitê verificou a permanência da tônica das obras estruturais, que, segundo Guimarães (2012), gerou preocupação com relação aos impactos ambientais e sociais que poderiam ser deflagrados.

Segundo o parecer das comissões técnicas do Comitê, aprovado pela Resolução ${ }^{\circ}$ 41, de fevereiro de 2011, a cooperação internacional trilhou caminhos equivocados, quando não compreendeu a real problemática dos desastres naturais no Vale do Itajaí e, também, ao se desviar de pontos discutidos e acordados nas discussões anteriores. Sobre a percepção da gênese dos desastres naturais, $o$ argumento é que a Jica não distinguiu inundações graduais das bruscas. Ao adotar essa metodologia, as médias de precipitação camuflam os extremos, os quais são relevantes, seja pela violência, seja por acarretarem os deslizamentos. Ao não considerarem pontos consensuados nos inúmeros debates públicos, as propostas contidas no relatório da Jica poderiam levar a conflitos já superados. (Guimarães, 2012, p. 13).

\footnotetext{
${ }^{5}$ A Fundação Agência de Água do Vale do Itajaí foi instituída em 2001 como uma entidade privada, comunitária e sem fins lucrativos. A sua finalidade é a atividade de caráter técnico e administrativa destinada principalmente no que diz respeito à operacionalização do Comitê do Itajaí, exercendo o papel de sua secretaria executiva. Em 2011, ela adotou o nome fantasia de Fundação Piava, decorrente da repercussão positiva do Projeto Piava, executado entre 2005 e 2010. Disponível em: http://www.cbhriodoisrios.org.br/downloads/capacitacao-vol4.pdf. Acessado em: 25 nov. 2019.
} 
Apesar da crítica, o Comitê reconheceu a importância do trabalho e recomendou a revisão das propostas de maneira a compatibilizá-las com os instrumentos de planejamento dos setores de meio ambiente, hídricos e da defesa civil. A nova proposta estadual elaborada com a JICA foi divulgada em janeiro de 2012, em meio às pressões ocasionadas pela ocorrência das catástrofes de 2011. Segundo Guimarães (2012), os novos acontecimentos aumentaram a relevância desse projeto e a urgência na adoção de novas medidas. O agente principal em meio a essa tensão foi o Conselho Estadual de Recursos Hídricos (CERH), que lançou resolução em 2011, reforçando a necessidade de apresentar os resultados levantados pela JICA. Porém Guimarães (2012) aponta que a proposta não teve tempo suficiente para a revisão sugerida pelo Comitê do Itajaí.

\section{O domínio do interesse empresarial no enfrentamento dos desastres em Santa Catarina}

Dados da Secretaria de Estado de Proteção e Defesa Civil de Santa Catarina ${ }^{6}$ permitiram afirmar que Guimarães (2012) estava certo em suas suspeitas: o governo do estado não considerou as recomendações do Comitê do Itajaí. A primeira evidência que corresponde a essa análise vem da Diretoria de Projetos Especiais e Reconstrução $(\text { DIPES })^{7}$, relatando que a linha de ação adotada pela secretaria estadual seguiu a matriz do Projeto JICA, cujos resultados já haviam sido entregues em junho de 2011. É esse projeto que sustenta a proposta do Projeto de Prevenção e Mitigação de Desastres na Bacia do Rio Itajaí, com destaque para três ações governamentais: 1) Medidas estruturais de contenção do rio; 2) Medidas estruturais de melhoramento do fluxo do rio; e 3) Instalação do Sistema de Monitoramento, Alerta e Alarme, considerada a única medida não estrutural do projeto. Essa proposta foi lançada em 2012, cuja implantação exigia investimentos estimados em 1,5 bilhão de reais.

Com o projeto de prevenção e mitigação pronto, o governo formou uma comissão que foi ao Japão buscar recursos para implantar o novo plano diretor. Os japoneses já haviam sinalizado interesse em financiar o projeto devido à relação técnica estabelecida. Na visita ao governo japonês para verificar os termos do acordo, a proposta não foi aceita pelo governo catarinense, pois os japoneses queriam que os valores fossem devolvidos com juros cobrados dos países emergentes e não com juros pagos pelos países subdesenvolvidos. Isso o fez recuar da proposta inicial e voltar sua atenção ao governo federal. Em Brasília, o projeto foi aprovado, sendo firmado o contrato: sua primeira fase receberia o investimento de mais de 600 milhões de reais.

A segunda evidência encontrada está disponível no Plano Plurianual Estadual 2012-2015. Nele, encontra-se a previsão orçamentária de investimentos no valor de 200 milhões de reais, oriundos do Fundo Estadual de Proteção e Defesa Civil, para realização da primeira fase do Projeto JICA. No total, os investimentos chegaram a 800 milhões de

\footnotetext{
${ }^{6}$ Dados coletados para a Dissertação de Mestrado defendida no Mestrado Profissional do Programa de Pós-Graduação em Planejamento Territorial e Desenvolvimento Socioambiental - PPGPLAN, do Centro de Ciências Humanas e da Educação - FAED, da Universidade do Estado de Santa Catarina - UDESC, como requisito para obter o grau de Mestre em Planejamento Territorial e Desenvolvimento Socioambiental.

${ }^{7}$ Órgão da Secretaria de Estado de Santa Catarina em 2015.
} 
reais, vinculados ao Programa Pacto por Santa Catarina lançado pelo governo de Raimundo Colombo (2011-2015 e 2016-2018) como o maior programa de investimentos governamentais da história do estado de Santa Catarina.

Ao analisar o plano plurianual, verifica-se que $86 \%$ desses investimentos foram direcionados às fases de prevenção, mitigação e preparação, sendo apenas $4 \%$ às fases de resposta e reconstrução. Somado os valores disponíveis nos cofres públicos com os que foram financiados, aumentava o percentual, conforme ilustra a Figura 2.

Os dados indicam o total desequilíbrio nos planos governamentais, principalmente a destinação de poucos recursos para a fase de reconstrução. Surge então uma quarta consequência do modelo de tecnificação da defesa civil adotado em Santa Catarina.

Informações publicadas em três reportagens, apresentadas nos dias 27 e 28 de abril e no dia 1 de maio de $2015^{8}$, e veiculadas no Jornal do Almoço da Rede Brasil Sul de Televisão (RBS TV), filial de Blumenau, apontaram a disparidade do orçamento público. Na primeira reportagem, a prestação da Prefeitura Municipal de Ilhota foi recusada e os parcos recursos destinados à reconstrução de 2008 precisaram ser devolvidos aos cofres públicos. Com a reprovação das contas, o município perdeu
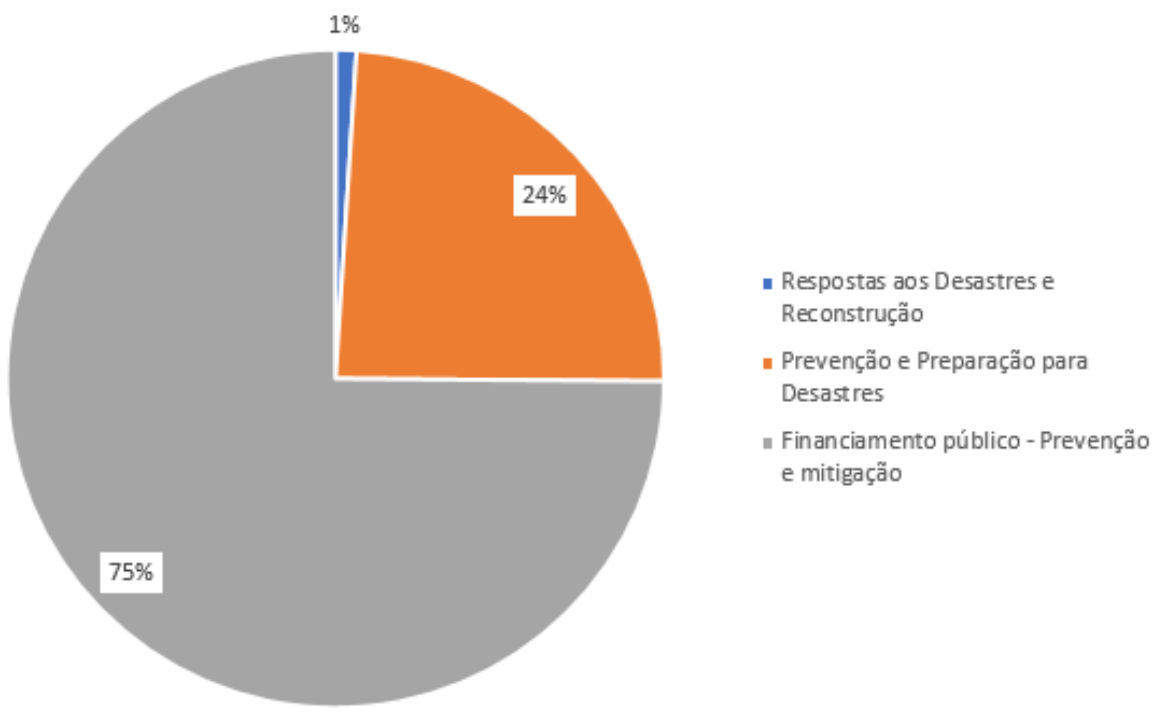

FIGURA 2 - Distribuição orçamentária de acordo com o ciclo de gestão em defesa civil.

FONTE: Elaborado pelos autores (Santa Catarina, 2011).

\footnotetext{
${ }^{8}$ Disponíveis em: http:/g1.globo.com/sc/santa-catarina/jornal-do-almoco/videos/ sob os títulos: moradores de loteamento de Gaspar sofrem com falta de estrutura há seis anos; Moradores de ruas danificadas na tragédia de 2008 ainda sofrem com problemas, em Blumenau; e Índios acampados em barragem de José Boiteux pedem ajuda há quase um ano. As reportagens foram acessadas em: 10 maio, 2015.
} 
a capacidade de investir $\mathrm{R} \$ 4,5$ milhões de reais em medidas de recuperação.

A segunda reportagem mostrou a situação de 70 famílias, desabrigadas em 2008, no município de Gaspar, onde se encontravam reunidos num loteamento às margens da BR-470, conhecido como Loteamento das Arábias, em referência à doação das casas feita pelo consulado da Arábia Saudita. Os moradores do local contavam a sua situação, reivindicando a infraestrutura básica de moradia. $\mathrm{A}$ reportagem mostrava como as famílias conviviam com a falta de saneamento básico, calçamento, serviços públicos de saúde, educação, transporte etc.

A mesma reportagem retratou também a situação de Blumenau, mostrando as cicatrizes do desastre de 2008. A cidade não fora totalmente recuperada, em pleno ano de 2015, permanecendo várias áreas danificadas sem investimentos para recuperação da infraestrutura urbana. Em resposta ao Jornal do Almoço, o secretário de obras de Blumenau declarou publicamente que o processo de reconstrução de 2008 estava legalmente encerrado, por isso, não seria mais possível finalizar a reconstrução dos danos em relação àquela tragédia.

Na última reportagem, são mostradas imagens das famílias indígenas que continuavam lutando por seus direitos e, para pressionar o governo estadual, estavam acampadas há seis meses (em 2015) na barragem de José Boiteux. A ocupação foi uma tentativa de chamar a atenção para a carência da população indígena e reivindicar a reparação do que lhes fora tirado durante o ciclo das barragens. Em resumo, os governos municipal, estadual e federal praticamente apagaram dos seus orçamentos qualquer medida, linha de crédito, ou mesmo programas destinados a vários setores da população, marginalizando-as. A disparidade vai além: ao analisar todos os valo- res relacionados às ações de prevenção, mitigação e preparação projetados pelo governo Raimundo Colombo, vê-se a tônica das medidas estruturais, principalmente em obras de engenharia, que haviam sido criticadas em outro momento pelo Comitê do Itajaí, como proposta atual.

A Tabela a seguir mostra essa tendência, na relação das ações retiradas do Plano Plurianual.

A primeira fase descrita pelo plano como "Projeto de medidas de prevenção dos desastres na Bacia do Rio Itajaí - JICA 1", correspondeu a sete medidas, das quais seis foram estruturais e uma considerada não estrutural, que se trata, na verdade, da instalação do Sistema de Monitoramento, Alerta e Alarme. Essa tendência é detalhada na Tabela a seguir:

A Tabela 2 mostra que 98\% dos valores destinados à prevenção e mitigação se relacionam com as propostas do plano diretor definidas pelos estudos da JICA e que tratam de um complexo estrutural de contenção e melhoramento fluvial no Vale do Itajaí seguindo as medidas da década de 1920 de Otto Rohkohl e Adolf Odebrecht. A pesquisa apontou a análise segundo a qual o governo catarinense segue atualmente, em linhas gerais, três eixos de organização de confrontação dos desastres: o primeiro relacionado com a execução do Projeto de Prevenção e Mitigação de Desastres na Bacia do Rio Itajaí; o segundo, com a construção de um plano diretor de mesma envergadura para formar o Plano Diretor da Estiagem, divulgado em março de 2015; com a elaboração de um diagnóstico sobre as estiagens no grande Oeste catarinense; e o terceiro, com a construção de um centro de gestão de risco e desastre, a partir da implantação do Sistema de Monitoramento, Alerta e Alarme. 
TABELA 1 - Lista de ações previstas no Plano Plurianual 2012-2015.

Descrição

Projeto de medidas para prevenção dos desastres na Bacia do Rio Itajaí - JICA1 (primeira fase)

$884.800 .000^{9} \quad 98 \%$

Estruturação das Unidades de Proteção Civil

$15.000 .000 \quad 2 \%$

Promoção da educação continuada em proteção e defesa civil

$1.600 .000 \quad 0 \%$

Apoio financeiro e custeio de despesas de unidades municipais de proteção civil

$1.600 .000 \quad 0 \%$

Contratação de consultoria de apoio institucional, estudos e projetos para PPD

$1.200 .000 \quad 0 \%$

Implantação do sistema de inteligência em proteção e defesa civil

$400.000 \quad 0 \%$

Apoio técnico e financeiro na estruturação das Defesas Civis nos municípios - SDR - Timbó

$400.000 \quad 0 \%$

Implantação do Sistema de Monitoramento e Alerta

$140.000 \quad 0 \%$

Apoio às ações da gestão de produtos perigosos

$80.000 \quad 0 \%$

Total

$905.220 .000,00 \quad 100 \%$

FONTE: Elaborado pelos autores (Santa Catarina, 2011). ${ }^{10}$

${ }^{9}$ Valor total orçado no Plano Plurianual 2012-2015, mais a proposta de investimentos levantados pelo Programa Pacto por Santa Catarina.

${ }^{10}$ As informações foram organizadas por Unidade Orçamentária da Administração Direta, Administração Indireta (Empresas, Autarquias e Fundações) e os demais Poderes do Governo do Estado de Santa Catarina. 
TABELA 2 - Parte do Projeto de Prevenção e Mitigação de Desastres na Bacia do Rio Itajaí apresentado em fevereiro de 2012 pelo governo do estado de Santa Catarina.

\begin{tabular}{|c|c|c|c|}
\hline Medida 1 & 1 & $\begin{array}{l}\text { Sistema de monitoramento, alerta e } \\
\text { alarme }\end{array}$ & $\begin{array}{l}\text { Controle } 24 \text { horas das áreas de risco por meio de } \\
\text { radar meteorológico, mapeamento e planos de } \\
\text { contingência. }\end{array}$ \\
\hline Medida 2 & 1 & Sobrelevação de 2 Barragens & $\begin{array}{l}\text { Reduzir o escoamento, ampliando o armazenamen- } \\
\text { to de água e retardando a elevação dos rios. }\end{array}$ \\
\hline Medida 3 & 1 & $\begin{array}{l}\text { Construção de } 2 \text { comportas e diques no } \\
\text { canal antigo do Rio Itajaí-Mirim }\end{array}$ & $\begin{array}{l}\text { Retardar o acúmulo e possibilitar o escoamento } \\
\text { das águas com segurança. }\end{array}$ \\
\hline Medida 4 & 1 & Melhoria no Rio Itajaí-Mirim & $\begin{array}{l}\text { Intervenções com } 1 \mathrm{~km} \text { de extensão para prevenir } \\
\text { enchentes e inundações. }\end{array}$ \\
\hline Medida 7 & 1 & $\begin{array}{l}\text { Construção de } 2 \text { barragens de médio } \\
\text { porte em Botuverá }\end{array}$ & $\begin{array}{l}\text { Contenção das enchentes e utilização de água para } \\
\text { irrigação. }\end{array}$ \\
\hline
\end{tabular}

FONTE: Santa Catarina, 2012. ${ }^{11}$

Sobre o sistema de monitoramento, destaca-se, durante o mês de abril de 2015, o registro de um tornado na cidade de Xanxerê, região do Oeste catarinense. Curiosamente esse incidente não tratou de enchentes, movimentação de massas, nem de estiagem. O que ocorreu foi um vendaval, que, segundo estimativa da Epagri/Ciram ${ }^{12}$, deve ter alcançado a velocidade de $200 \mathrm{~km} / \mathrm{h}$. No último relatório divulgado pela Secretaria de Proteção e Defesa Civil, esse acontecimento provocou, nas cidades de Xanxerê e Ponte Serrada, duas mortes, 616 desabrigados e cerca de 113,4 milhões de reais em danos financeiros ${ }^{13}$. Por ser de formação rápida, é de difícil previsão, por isso, o radar meteorológico instalado daria a previsibilidade apenas com duas horas de antecedência, evidenciando ainda mais a fragilidade das medidas de redução e mitigação adotadas.

\section{Conclusão}

A Política Nacional de Proteção e Defesa Civil de abril de 2012 marca a preocupação direta em destacar a proteção como o principal conceito que orienta a sua política, consciente de que as medidas

\footnotetext{
${ }^{11}$ Resumo do Projeto de Prevenção e Mitigação de Desastres na Bacia do Rio Itajaí apresentado em fevereiro de 2012.

${ }^{12}$ Disponível em: https://www.facebook.com/defesacivilsc/posts/572301286244830. Acessado em 17 maio 2015.

${ }^{13}$ Disponível em: http://www.defesacivil.sc.gov.br/index.php/ultimas-noticias/3551-relatorio-oeste-atualizado.html. Acessado em 17 maio 2015.
} 
de redução de riscos de desastres estão ligadas à prevenção. Porém, no processo de conformação dessa nova matriz, aparece com um conjunto de questões ligadas aos interesses dos atores envolvidos na construção dessa política, que podem ser percebidas com a sobreposição da participação social pelo debate técnico-científico. Há que se considerar a correlação de forças e as disputas no jogo do poder dos diferentes setores sociais envolvidos. Cada qual com seus meios para estabelecer domínio. O percurso percorrido para analisar o modelo de tecnificação da defesa civil em Santa Catarina, por meio do Projeto JICA, trouxe informações preciosas para compreender o que está envolvido para além da aparência consensual dos conceitos escritos na PNPDC.

Ao remontar as condições de emergência do Projeto JICA já era claro considerar o protagonismo dos setores empresariais na disputa pelo governo, o que ficou demarcado pela invocação do espírito empreendedor feito por Rohkohl. O seu papel foi fundamental para a organização e consciência de classe dos empresários do Vale do Itajaí, elaborando uma série de estratégias para defender seus interesses por meio do estado. A conquista de espaço no poder público veio inicialmente pela instrumentalização da comoção causada pelos desastres em força política e na produção de projetos capazes de aglutinar os anseios gerais em determinada direção. Por conseguirem dar respostas mais claras e efetivas aos problemas, gozaram de maior legitimidade, podendo encobrir os seus interesses como interesse geral da população.

O discurso técnico-científico tem lugar preciso na organização do poder público. Ele serviu para a conciliação entre os setores empresariais e as frentes de colonização do Alto Vale, na década de 1920.
Para orientar por várias vezes as ações do governo federal, como visto no ciclo das barragens, a partir de 1957, no acordo entre o Brasil e o Japão, por meio do Japan International Cooporation Agency (JICA) após as grandes enchentes de 1983-1984 e nos embates travados em vários momentos, como nos Seminários anteriores ao Plano Global Integrado de Defesa contra Enchentes (PLADE) de 1985.

Em todos os momentos, os setores empresariais defenderam seu projeto, investimentos estruturais em barragens e melhorias no fluxo do rio. $\mathrm{Na}$ fase de industrialização do capitalismo brasileiro, finalmente ascenderam ao controle do governo. Mesmo diante da experiência da redemocratização, que traz novos segmentos ansiosos por participação social, os setores empresariais mantiveram sua proposta de mitigação. Foram lançados vários programas que poderiam avançar nas medidas de redução de riscos e desastres e que chegaram a incorporar a revisão do PLADE na década de 1990, mas o que se viu foram recortes e a prevalência em determinadas medidas do Projeto JICA. Essa ação foi deliberadamente repetida no Plano Integrado de Prevenção e Mitigação de Riscos de Desastres Naturais na Bacia Hidrográfica do Rio Itajaí, após os desastres de 2008, mantendo o Projeto JICA como principal projeto de mitigação dos desastres em Santa Catarina.

A experiência indica um conjunto de consequências que podem ser destacadas. 1) O constante uso da calamidade como recurso para o aparelhamento do poder político pelos setores empresariais, mediante um processo que encobre a desigualdade da distribuição dos prejuízos. 2) O controle e afastamento da participação social nas políticas públicas, conformando o modelo tecnocrático de construção da política de defesa civil e definindo 
prevenção como medidas estruturais de melhoria das barragens e controle dos fluxos das cheias, e, como medidas não estruturais, a instalação de Sistema de Monitoramento, Alerta e Alarme. 3) A intensificação dos desastres, como ocorrido em 2008, no qual pode ser considerado o resultado de um processo deliberado de negligência e aplicação autoritária dos recursos públicos. A tragédia de 2008 coloca no banco dos réus o modelo de desenvolvimento adotado, sendo, portanto, mais do que uma tragédia anunciada. 4) A privatização cada vez maior das áreas da vida, representado pelo balcão de negócios que foram aplicados na política de defesa civil em Santa Catarina. Aqui há a mercantilização dos desastres, inclusive pela participação maciça do capital financeiro internacional, representado pela cooperação intercapitalistas entre Brasil e Japão. Novamente o discurso tecnocientífico passa a ser instrumento para a sobreposição das experiências e produções de conhecimento locais, tanto das crises como das pesquisas que já mostraram competência para produção de respostas mais interessantes das realizadas até o momento. E 5), a face mais perversa da política de defesa civil adotada, que é o sofrimento da população mais vulnerável, sendo cada vez mais vítima dos resultados dos desastres socioambientais, como os ocorridos em 2008.

Entre 2008 e 2015, já se vão sete anos de uma população refém de parcos recursos e ajuda humanitária de países “caridosos". Pessoas reféns de setores que, gozando dos seus interesses preservados, tentam apagar a história, jogando os problemas às margens da BR-101, fato que será recorrente, pois a tragédia continua mais que anunciada.

\section{Referências}

Ávila, M. R. R.; Mattedi, M. A. Desastre e território: a produção da vulnerabilidade a desastres na cidade de Blumenau/SC. URBE. Revista Brasileira de Gestão Urbana, 9, 187-202, 2017.

Casagrande Jr., E. Mortes e prejuizos do Vale do Itajaí: tragédia anunciada há mais de 150 anos, 2008. Disponível em: <http://www.agr.feis.unesp.br/defers/noticias/index. php?idnoticia=1228131497>. Acesso em: nov., 2019.

Chiarelli, J. R. Agência de Cooperação Internacional do Japão (JICA) como ferramenta política: mecanismos de integração regional. Porto Alegre, Trabalho de Conclusão de Curso (Bacharel em Ciências Sociais) - UFRGS, 2009.

Fraga, N. C. As Enchentes no Vale do Itajaí-Açu/SC: das obras de contenção à indústria da enchente - a problemática ambiental e a relação homem/natureza na busca de soluções. Revista Ra'e Ga, 5(V), 125-148, 2002.

Fraga, N. C.; Köhler, V. B. As enchentes no Vale do Itajaí-Açu/SC: das obras de contenção à indústria da enchente. Boletim de Geografia, 17, 81-92, 1999.

Frank, B. Uma abordagem para o gerenciamento ambiental da Bacia Hidrográfica do Rio Itajaí, com ênfase no problema das enchentes. Florianópolis, Tese (Doutorado em Engenharia) - UFSC, 1995.

FUNDAÇÃO AGÊNCIA DE ÁGUA DO VALE DO ITAJAÍ. Plano de recursos hídricos da bacia do Itajaí: caderno síntese. Blumenau: Fundação Agência de Água do Vale do Itajaí, 2010.

Guimarães, P. C. V. As enchentes em Santa Catarina e o aprendizado em políticas públicas. Brasília: ENAP - Casoteca de Gestão Pública, 2012.

JICA. Estudo preparatório para o projeto de medidas de prevenção e mitigação de desastres na bacia do rio Itajaí. Relatório Final. Florianópolis, 2011

Mattedi, M. A. As enchentes como tragédias anunciadas: impactos da problemática ambiental nas situações de emergência em Santa Catarina. Campinas, Tese (Doutorado em Ciências Sociais) - Unicamp, 1999. 
SANTA CATARINA. Projeto de Prevenção e Mitigação de Desastres na Bacia do Rio Itajaí. Florianópolis, 2012

SANTA CATARINA. Relatório do Plano Plurianual 2012-2015. Florianópolis, 2011. Disponível em: <http:// www.sef.sc.gov.br/transparencia/relatorio/50>. Acessado em: nov. 2019.
Skidmore, T. E. Brasil: de Getúlio a Castello 1930-1964. Tradução: Berilo V. São Paulo: Companhia das Letras, 2010.

Valencio, N. Elementos constitutivos de um desastre catastrófico: os problemas científicos por detrás dos contextos críticos. Ciência e Cultura, 68, 41-45, 2016. 